\title{
Vaccines for COVID-19 - state of the art
}

Eduardo Jorge da Fonseca Lima 1

iD https://orcid.org/0000-0002-2277-2840

Amalia Mapurunga Almeida 2

(D) https://orcid.org/0000-0001-5212-7634

Renato de Ávila Kfouri 3

https://orcid.org/0000-0002-3903-8140

1 Coordenador da pós graduação latu sensu. Instituto de Medicina Integral Prof. Fernando Figueira. Rua dos Coelhos, 300. Boa Vista. Recife, PE, Brasil. CEP: 50.070-902. E-mail: eduardojorge@imip.org.br

2 Instituto de Medicina Integral Prof. Fernando Figueira. Recife, PE, Brasil.

3 Departamento de Imunizações. Sociedade Brasileira de Pediatria.Rio de Janeiro, RJ, Brasil.

\begin{abstract}
Vaccine candidates against COVID-19 have diverse compositions, from traditional inactivated virus vaccines to various new-generation vaccines. Currently, approximately 175 research teams worldwide are studying various vaccine possibilities as the necessityto vaccinate the entire population against the SARS-CoV-2 virus is urgent. Although, the development of a safe and effective COVID-19 vaccine is not easy, the manufacturing, distribution, and administration of the vaccine can also face extraordinary challenges. In this review, we enhance some of the current knowledge regarding the clinical trial phases on different COVID-19 vaccine candidates, its potential strengths and disadvantages, and to discuss ethical aspects and their chances of success in large-scale applications.
\end{abstract}

Key words Vaccines, COVID-19, Pandemic

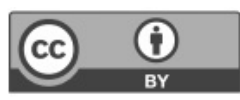




\section{Introdução}

The COVID-19 pandemic has the most promising and eagerly awaited hope in vaccines. ${ }^{1}$ An effective vaccine will be crucial in controlling the pandemic, which has already affected about thirty-one million individuals and killed one million people worldwide. ${ }^{2}$ Ensuring immunity will allow us to be less concerned about social distancing and all its major socioeconomic implications. ${ }^{3}$

The genetic sequence of the virus released early on January 11, 2020 triggered intense global research activity to develop a vaccine against the disease. ${ }^{2}$ The impactof the humanitarian and economic scale of the COVID-19 pandemic has driven the use of new platforms on vaccine technology to accelerate the research, and the first vaccine candidate entered the clinical trials for humans in mid-March 2020 at an unprecedented speed. 4

The speed on research means that vaccines may be available in an emergency by early 2021 . If this occurs, it will be the fastest vaccine development program ever seen in history. It will represent a fundamental shift in the traditional trajectory of vaccine release, which takes about ten years to implement.5,6 In addition, new paradigms will be needed, involving adaptations in the development phases, regulatory processes and large-scale of manufacturing capacity. 4

The vaccine production process follows the phases of a clinical study, with pre-clinical steps, performed in laboratories, in general, in animal models, aiming to evaluate the dose and toxicity in this population. The clinical trials, in humans, are divided into three stages. Phase 1 studies aim to evaluate the safety of the product, while phase 2 studies evaluate safety, dose and frequency of administration, as well as its immunogenicity. Phase 3 trials have as main outcome evaluation on the efficacy of the product, through controlled and randomized clinical trials involving thousands of volunteers. After the scientific publication of these data, the vaccine candidate is submitted to evaluation by regulatory agencies for further production and distribution. Finally, phase 4 or post-licensing studies estimate the effects and adverse events after a largescale use of the vaccine in the target population. ${ }^{7}$ Each step in this process lasts an average of several months to years.

Reducing the entire process to a period of 12 to 18 months is unprecedented. But is this all possible without damaging the effectiveness and safety?

About 175 research teams around the world are studying various vaccine platforms. Vaccine development programs are continuously updated by the World Health Organization (WHO), with projects coming from public and private sources.

Several production of technologies are being evaluated, including nucleic acids (DNA and RNA), use of viral vectors (replicants and non-replicants), viral vaccines (attenuated or inactivated), and protein vaccines (recombinant or PLV - virus-like particles - technology used in HPV vaccine). ${ }^{8}$ Some of these platforms have never been used in currently licensed vaccines, but experience exists in areas such as oncology, and new opportunities for vaccine production are emerging with increased manufacturing speed. ${ }^{6}$ However, this process, like everything that is new and untested, requires caution to not offer false hope at such a difficult time for humanity.

Most vaccines studied for COVID-19 aim to induce neutralizing antibodies against the viral subunits, most of them targeting to the RBD region (Receptor Binding Domain) of the most conserved virus protein, Spike (S), thus preventing the capture of the virus by the human ACE2 receptor (converting enzyme of angiotensin 2). ${ }^{9}$ It is not clear how the $\mathrm{S}$ protein variants used in different vaccine candidates relate to each other or to the genomic epidemiology of the disease. 6

Vaccines with viral vectors: Non-replicants Adenovirus have been the main viral vectors used in the development platforms for COVID vaccines. They can be human (Ad5 and Ad26) or apes (Chimpanzees ChAd). 10

Aviral vector-based, ChAdOx1 nCoV-19 vaccine developed at Oxford University in England in partnership with the AstraZeneca laboratory induces a robust immune response, including cellular response, after the application of two doses. It uses, as a vector, a non-replicant chimpanzee adenovirus that expresses the SARS-CoV-2 S protein. Phase 1 and 2 studies involving a control group with meningococcal conjugate vaccine in healthy adults showed a specific T-cell response on day 14 after application, with neutralized antibodies detected between 91 and $100 \%$ of the patients presenting an acceptable and safety profile. ${ }^{11}$ Currently, it is in phase 3 studies involving health professionals and high exposure groups from the United Kingdom and four other countries, including Brazil. The emergence of a serious and unexpected adverse event in a volunteer who presented with a transverse myelitis condition caused the laboratory to temporarily suspend phase 3 study at all the centers for further analysis of the case. After evaluation by the external 
monitoring committee, a causal relationship between the vaccine and the adverse event was removed and the study continues worldwide.

The American laboratory Johnson \& Johnson is also testing a vaccine based on viral vectors. The results of phase 1 and 2 tests were encouraging and phase 3 tests started in August on a global scale, including a research center in Brazil. 12

Other viral vector-based vaccines are already released for restricted use in certain population groups in China and Russia. The Chinese laboratory CanSino has released phase 1 studies demonstrating promising results with a vaccine that uses $\mathrm{Ad} 5$ as a vector, but no phase 3 studies have been published and the vaccine is currently approved in that country for exclusive use for the Chinese military. 13

Also with the technology of adenovirus use, vaccination of health professionals and teachers ofthe vaccine produced by the Gamaleya Institute in Moscow has been initiated. A recently published Phase $1 / 2$ study tested 02 vaccine formulations based on 02 adenovirus subtypes and all the participants produced antibodies against the SARS-CoV-2 glycoprotein with a $100 \%$ seroconversion rate after 42 days of application. The cell response on day 28 was also evaluated, with the detection of CD4 and CD8 proliferation in all the studied population. 14 The Russian vaccine uses Ad26 as a viral vector in the first and Ad5 in the second dose. There is a proposal to extend vaccination to all Russian citizens in October and the government of the state of Paraná, Brazil is negotiating access to the so-called Sputnik $V$ vaccine.

Genetic vaccines: The messenger RNA vaccines have shown, in general, an excellent safety profile and with good cellular and humoral immune responses. It has the advantage of being produced on a larger scale, because they are synthetic products, and it has the disadvantage of being products that require freezing conservation. The RNAvaccine is wrapped in a lipidic layer, thus avoiding its degradation. So far, no DNA vaccine has reached phase 3 in the clinical trials. 10

The American laboratoryModern, in partnership with the National Institutes of Health (NIH), initiated the clinical testing of its messenger RNA-based vaccine (mRNA-1273) only two months after the identification of the virus sequence and published in July its phase $1 / 2$ study in human volunteers. The vaccine, which encodes the stabilized $\mathrm{S}$ protein, resulted in the production of a large amount of neutralized antibodies in all the participants studied, detected by two different methods, and with values similar to serum samples from convalescent patients with self-limited adverse events. ${ }^{15}$ Phase 3 study was initiated in June and aims to prevent the symptomatic disease of COVID-19.16

Also based on the mRNA, the vaccine produced by the American laboratory Pfizer, in partnership with the German biotechnology company BioNTech, demonstrated good response in inducing humoral and cellular immunity in its phase 1 and 2 studies. The results showed titers of neutralized antibodies on average 1.8 to 2.8 times higher when compared to the panel of human serum convalescents of COVID19.17 The study of phase 3 began in August and involves about 30,000 participants in countries such as Brazil, Argentina and Germany, in addition to the United States.

Viral vaccines: traditional technologieson vaccine production such as live attenuated and inactivated viruses have been used in several clinical trials. Concerns about the biosecurity of attenuated vaccines have made studies difficult with this platform, and some inactivated vaccines are already in Phase 3 testing. 10

The Chinese laboratory Sinovac vaccine uses the classical inactivated virus platform, with cell culture of the virus in vero cells with subsequent inactivation. In Brazil, it has established a partnership with the government of the State of São Paulo, through the Butantan Institute, and is being tested on health professionals from 12 Brazilian centers. Published in early August, phase 1 and 2 study tested different schemes by varying doses and applying intervals, demonstrating seroconversion in $100 \%$ of those evaluated in phase 1 study and those receiving a second dose at 21 days in phase 2 studies. 18 There were low rates of adverse effects and the vaccine was approved for emergency use by health professionals in China.

Two other inactivated vaccines from Sinopharm laboratory has also began their phase 3 studies.

Protein vaccines: the classic technology of using viral proteins (structural and non-structural) in vaccine manufacturing has also been tested for COVID. Sub-unit or virus-like particle (NPV) vaccines have already reached clinical phases. ${ }^{10}$

The Novavax laboratory vaccine uses a recombinant version of the $\mathrm{S}$ protein developed with the nanoparticle technology, associated with an adjuvant. Phase 1 and 2 trials demonstrated its safety and immunogenicity, authorizing the initiation of phase 3 studies.

In an unprecedented collaboration, two of the 
world's largest vaccine producers, Sanofi Pasteur (France) and GlaxoSmithKline (GSK-UK), joined forces to produce an adjuvanted protein unit vaccine, starting phase 1 and 2 studies in September.

Previous exposure to other coronaviruses can play a protective role through some degree of crossprotection, and can be one of the factors related to the disproportionality with which children are more exposed to common colds caused by other coronaviruses, are less affected by severe forms of the disease. 19

Vaccines such as BCG, oral polio, and triple viral polio may also, through modulation of the innate immune response, play some role in preventing severe forms of COVID-19, a phenomenon described as non-specific effects of vaccines; there are some studies seeking to evaluate this hypothesis. 20

To date, the best approach to demonstrate the effectiveness of a vaccine against COVID-19 is through clinical trials showing protection against the disease. Comparing this effectiveness between different vaccines will not be an easy task, as it will have to take into account differences in the population and study designs. Therefore, considering that only 10 of the vaccines in development have started their phase 3 studies, and many of these do not have a date for completion, we do not anticipate the availability of data that would allow us to answer at least in parts, "what is the ideal vaccine?". 21

Viruses can challenge vaccine manufacturers by quickly changing so that antibodies that act on one viral strain fail on another. The new coronavirus does not seem to undergo major changes, so a vaccine that proves to be effective should probably work in any country. 22 This does not mean, however, that this risk is ruled out, and caution should be considered in this regard.

Scientists are increasingly optimistic that a vaccine can be produced in record time, but making and distributing it are other greater challenges. Another condition, which should not be neglected, are the possible barriers in reaching adequate vaccine coverage. Decreasing the number of cases when a vaccine is licensed, hesitation to receive a new product, and lack of confidence in political and health authorities in many countries can act as major barriers. ${ }^{23}$

The World Health Organization (WHO) has made a proposal to the European Union recommending a voluntary pool of patents, which would put pressure on companies to give up their monopolies of the vaccines they have developed.24 WHO initiative in partnership with GAVI Global Alliance for Vaccines (COVAX) has united countries together in a vaccine delivery fund on an equitable basis for the countries that signed the agreement.

Oxfam, an international charity, has published an open letter to 140 world leaders and experts calling for a "people's vaccine" to be made available at"no cost to all people in all the countries". Helen Clark, former Prime Minister of New Zealand, who also signed the letter, commented that "vaccines against COVID-19 must be a public good and we are not safe until everyone is safe". 25

Vaccine researchers are concerned that amidst the desire to end theCOVID-19 pandemic, vaccine producers have been overly enthusiastic about the chances of their products working. 23

Another key aspect is the vaccine developers' profile. Just over half of the vaccine candidates are being developed by private companies, while about $45 \%$ of the projects are led by universities, the public sector and other non-profit organizations, of which about $50 \%$ are still in the pre-clinical phase. In addition, while several developers are multinational companies with extensive vaccine experience, many of the major groups of COVID-19 vaccine are small and/or inexperienced in a large-scale of immunobiological manufacturing. 6

About 33 countries are developing research to produce a vaccine against SARS-CoV-2.

Table 1 presents the vaccinecandidates for COVID-19 that are in phase 3 with details of its platforms, laboratories and developing countries. Of these ten projects, four are North American, four Chinese, one English and one Russian. North America and Asia (excluding China) account for about $30 \%$ of the research, while China accounts for $10 \%$. The United States is the country with the largest number of research in the area, totalizing around $20 \%$, a value similar to all the studies in Europe. Currently, there is little involvement and resources allocated to the vaccine research in Africa and Latin America, which collectively account for about $6 \%$ of the research

Ensuring vaccines are safe and effective requires much testing, careful planning and execution. All of us are vulnerable to the new coronavirus, except (probably) those who have already had the disease. In phase 3 vaccines currently under study, two doses are needed for better immunogenicity. Thus, more than 15 billion doses may be needed for the world to be protected from COVID-19.26

Some gaps in knowledge, especially regarding the immune response to the virus, are still being filled out. 21 The correlate protection against the disease, the exact role that cell immunity plays in 
immune response, the duration of neutralizing antibodies induced by a vaccine, the immune response in different age groups, and the possibility of developing antibodydependent enhancement (ADE) secondary to vaccine application are unknown. 26,27

Ethical aspects related to clinical research should also be considered in a pandemic scenario. Would it be possible to shorten the observation and follow-up time in a study? Is voluntary exposure to the virus after the administration of a vaccinecandidate ethi- cally acceptable? Does flexible licensing criteria impose any risk?28

One of the largest health regulatory agencies, the U.S. Food and Drug Administration (FDA), stated in June that for a vaccine to be approved, there must be evidence of reduced occurrence and severity of disease in at least $50 \%$ of patients. ${ }^{21}$ Considering the average time to complete clinical trials and the urgent need for vaccine protection, there are strands that advocate that such approval should be based

Table 1

Vaccine Candidatesfor COVID-19 in phase 3 - Platforms, laboratories and developing countries. Recife, 2020

\begin{tabular}{|c|c|c|c|}
\hline Vector viral & Genetic-RNA & Proteins & Inactivated Viral \\
\hline $\begin{array}{l}\text { AstraZeneca / Oxford (United } \\
\text { Kingdom) Chimpanzee Adenovirus } \\
\text { (ChAd) }\end{array}$ & $\begin{array}{c}\text { Pfizer / BioNTech (Germany) } \\
\text { messenger RNA }\end{array}$ & $\begin{array}{c}\text { Novavax (United States) } \\
\text { Subunits }\end{array}$ & Sinovac (China) \\
\hline $\begin{array}{l}\text { CanSino Biological (China) Human } \\
\text { Adenovirus type } 5 \\
\text { (Ad5) }\end{array}$ & $\begin{array}{l}\text { Modern (United States) } \\
\text { messenger RNA }\end{array}$ & & Sinopharm Wuhan (China) \\
\hline $\begin{array}{l}\text { Gamaleya (Russia) } \\
\text { Human Adenovirus types } 5 \text { and } 26 \\
\text { (Ad5 and Ad26) }\end{array}$ & & & Sinopharm Beijin (China) \\
\hline $\begin{array}{l}\text { Jansen (United States) } \\
\text { Human Adenovirus type } 26 \\
\text { (Ad26) }\end{array}$ & & & \\
\hline
\end{tabular}

only on antibody levels or other biomarker and not on clinical data. However, additional knowledge of the immunology and vaccine response to SARSCoV-2 that is reasonably related to the disease protection is still needed to consolidate such a proposal.21,29

There are also popular and political movements that advocate that the population should have access to unapproved substances. Since this is a scheme of mass vaccination of a healthy population against a disease that sometimes manifests itself in a mild or asymptomatic manner, even if only a small number of patients evolve with severe reactions, anaphylaxis or ADE, the results could be catastrophic. 30

Therefore, we cannot underestimate the importance of safety studies, which involve thousands of patients in order to detect severe adverse reactions, even more when they involve production of technologies never used. 29

Appropriate communication with the population, informing the real benefits of a vaccine, its limitations and the importance of individual and collective protection will be a great challenge to be faced, due to geopolitical issues involved. Confidence in the vaccines must be maintained at any cost, or we will put at risk all the achievements in control and elimination and diseases around the world.

Strong international coordination and cooperation among researchers, regulators, policymakers, financiers, public health agencies and governments will be needed to ensure that promising vaccines can be manufactured in sufficient quantities and supplied equitably to all affected areas, particularly in economically less advantaged countries. ${ }^{3}$

There are many scientific, ethical and political challenges to overcome. We do not yet know whether there will indeed be a successful vaccine against SARS-CoV-2, but we can be sure that the efforts involving its formulation and production are unprecedented. 


\section{Authors' contribution}

Fonseca Lima EJ and Kfouri RA participated in the literature review, elaborationof the article and final review. Almeida AM participated in the literature review and preparation of the article. All authors approved the final version of the article.

\section{References}

1. Gao Q, Bao L, Mao H, Wang L, Xu K, YangM, et al. Rapid development of na inactivated vaccine for SARS-CoV-2 [Internet]. Microbiology; 2020 Apr [cited 2020 Oct 14]. Available from: http://biorxiv.org/lookup/doi/10.1101/2020.04.17.046375

2. Frederiksen LSF, Zhang Y, Foged C, Thakur A. The Long Road Toward COVID-19 HerdImmunity: Vaccine Platform Technologies and Mass Immunization Strategies. Front Immunol. 2020; 11: 1817.

3. Yamey G, Schäferhoff M, Hatchett R, Pate M, Zhao F, McDade KK. Ensuring global accessto COVID-19 vaccines. Lancet. 2020; 395 (10234): 1405-6.

4. Lurie N, Saville M, Hatchett R, Halton J. Developing Covid-19 VaccinesatPandemicSpeed. N Engl J Med. 2020; 382 (21): 1969-73.

5. Sharpe HR, Gilbride C, Allen E, Belij-Rammerstorfer S, Bissett C, Ewer K, et al. The early landscape of coronavirus disease 2019 vaccine development in the UK and rest of the world. Immunology. 2020; 160 (3): 223-32.

6. Thanh Le T, Andreadakis Z, Kumar A, Gómez Román R, Tollefsen S, Saville M, et al. The COVID-19 vaccinedevelopmentlandscape. Nat Rev Drug Discov. 2020; 19 (5): $305-$ 6

7. Stevanim, Luiz Felipe. Como nasce uma vacina. Radis Fiocruz 2020; (216): 18-9.

8. Mukherjee R. Global efforts on vaccines for COVID-19: Since, sooner or later, we all will catch the coronavirus. J Biosci. 2020; 45 (1): 68.

9. Caddy S. Developing a vaccine for covid-19. BMJ. 2020; $\mathrm{m} 1790$.

10. Krammer F. SARS-CoV-2 vaccines in development. Nature. 2020; 586: 516-27. Available from: http:/www.nature.com/articles/s41586-020-2798-3

11. Folegatti PM, Ewer KJ, Aley PK, et al Safetyandimmunogenicityofthe ChAdOx 1 nCoV-19 vaccine against SARS-CoV-2: a preliminaryreportof a phase 1/2, single-blind, randomised controlled trial. Lancet. 2020; 396 (10249): 467-78

12. Mercado NB, Zahn R, Wegmann F, Loos C, Chandrashekar A, Yu J, et al. Single-shot Ad26 vaccine protectsagainst SARS-CoV-2 in rhesus macaques. Nature. 2020; 586: 5838. Available from: http://www.nature.com/articles/s41586020-2607-z
13. Zhu F-C, Li Y-H, Guan X-H, Hou L-H, Wang W-J, Li J-X, et al. Safety, tolerability, and immunogenicity of a recombinant adenovirus type-5 vectored COVID-19 vaccine: a dose-escalation, open-label, non-randomised, first-inhuman trial. Lancet. 2020; 395 (10240): 1845-54.

14. Logunov DY, Dolzhikova IV, Zubkova OV, Tukhvatullin AI, Shcheblyakov DV, Dzharullaeva AS, et al. Safety and immunogenicity of an rAd26 and rAd5 vector-based heterologous prime-boost COVID-19 vaccine in two formulations: two open, non-randomised phase $1 / 2$ studies from Russia. Lancet. 2020; 396 (10255): 887-97.

15. Jackson LA, Anderson EJ, Rouphael NG, Roberts PC, Makhene M, Coler RN, et al. An mRNA Vaccine against SARS-CoV-2 - Preliminary Report. N Engl J Med. 2020; NEJMoa2022483. Available from: https://www.nejm.org/doi/pdf/10.1056/NEJMoa2022483

16. Moderna. Moderna Advances Late-Stage Development of its Vaccine (mRNA-1273) Against COVID-19 [Internet]. 2020 [cited 2020 Sep 7]. Available from: https://investors.modernatx.com/node/9251/pdf

17. Mulligan MJ, Lyke KE, Kitchin N, Absalon J, Gurtman A, Lockhart S, et al. Phase 1/2 Study to Describe the Safety and Immunogenicity of a COVID-19 RNA Vaccine Candidate (BNT162b1) in Adults 18 to 55 Years of Age: Interim Report [Internet]. Infectious Diseases (except HIV/AIDS); $2020 \mathrm{Jul}$ [cited 2020 Oct 14]. Available from: http://medrxiv.org/lookup/doi/10.1101/2020.06.30.2014257 0

18. Xia S, Duan K, Zhang Y, Zhao D, Zhang H, Xie Z, et al. Effect of an Inactivated Vaccine Against SARS-CoV-2 on Safety and Immunogenicity Outcomes: Interim Analysis of 2 Randomized Clinical Trials. JAMA. 2020; 324 (10): 95160 .

19. Grifoni A, Weiskopf D, Ramirez SI, Mateus J, Dan JM, Moderbacher CR, et al. Targets of T Cell Responses to SARS-CoV-2 Coronavirus in Humans with COVID-19 Disease and Unexposed Individuals. Cell. 2020; 181 (7): 1489-1501.e15.

20. Escobar LE, Molina-Cruz A, Barillas-Mury C. BCG vaccine protection from severe coronavirus disease 2019 (COVID-19). Proc Natl Acad Sci USA. 2020; 117 (30): 17720-6.

21. U.S. Department of Health and Human Services, Food and DrugAdministration, Center for Biologics Evaluation and 
Research. Development and Licensure of Vaccines to Prevent COVID-19 [Internet]. 2020 [cited 2020 Sep 5]. Available from: https://www.fda.gov/regulatory-information/search-fda-guidance-documents/development-andlicensure-vaccines-prevent-covid-19

22. Dearlove B, Lewitus E, Bai H, Li Y, Reeves DB, Joyce MG et al. A SARS-CoV-2 vaccine candidate would likely match all currently circulating strains [Internet]. Evolutionary Biology; 2020 Apr [cited 2020 Oct 14]. Available from: http://biorxiv.org/lookup/doi/10.1101/2020.04.27.064774

23. Haq EU, Yu J, Guo J. Frontiers in the COVID-19 vaccines development. Exp Hematol Oncol. 2020;9 (1): 24.

24. Natalie Stoianoff. Whoever invents a coronavirus vaccine will control the patent - and, importantly, who gets to use it 2020 [Internet]. theconversation.com. 2020. Available from: https://theconversation.com/whoever-invents-a-coronavirus-vaccine-will-control-the-patent-and-importantlywho-gets-to-use-it-138121

25. Uniting behind a people's vaccine against COVID-19 [Internet]. unaids.org. 2020. Availablefrom: https://www.unaids.org/en/resources/presscentre/featuresto ries/2020/may/20200514_covid19-vaccine-open-letter
26. Amanat F, Krammer F. SARS-CoV-2 Vaccines: Status Report. Immunity. 2020 14; 52 (4): 583-9.

27. Alwis R, Chen S, Gan ES, Ooi EE. Impact of immune enhancement on Covid-19 polyclonal hyperimmuneglobulin therapy and vaccine development. EBioMedicine. 2020; 55: 102768.

28. Jamrozik E, Selgelid MJ. COVID-19 humanchallengestudies: ethicalissues. Lancet Infect Dis. 2020; 20 (8): e198203.

29. Avorn J, Kesselheim A. Regulatory Decision-making on COVID-19 Vaccines During a Public Health Emergency. JAMA. 2020; 324 (13): 1284-5.

30. Tetro JA. Is COVID-19 receiving ADE from other coronaviruses? Microbes Infect. 2020; 22 (2): 72-3.

Received on October 13, 2020

Approved on November 1, 2020 